\title{
Correlation of Clinical Features, Laboratory Finding, and Pelvic Ultrasonography of Pulmonary Tuberculosis Women with Infertility
}

This article was published in the following Dove Press journal: International Journal of General Medicine

\author{
Tita Husnitawati Madjid' \\ Iqbal Ardhi' \\ Wiryawan Permadi ${ }^{1}$ \\ Hadi Susiarno' \\ Sofie Rifayani Krisnadi \\ Firman Fuad Wirakusumah' \\ Ida Parwati (D) ${ }^{2}$ \\ 'Department of Obstetrics and \\ Gynecology, Faculty of Medicine, \\ Universitas Padjadjaran/Dr. Hasan Sadikin \\ Hospital, Bandung, Indonesia; \\ ${ }^{2}$ Department of Clinical Pathology and \\ Laboratory Medicine, Faculty of Medicine, \\ Universitas Padjadjaran/Dr. Hasan Sadikin \\ Hospital, Bandung, Indonesia
}

\section{Video abstract}

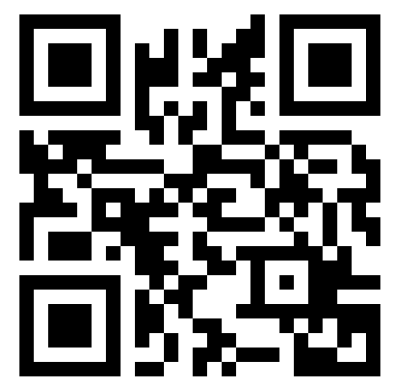

Point your SmartPhone at the code above. If you have a QR code reader the video abstract will appear. Or use: https://youtu.be/UdGOGRkOZWM

Correspondence: Tita Husnitawati Madjid Faculty of Medicine, Universitas Padjadjaran - Dr. Hasan Sadikin Hospital, Jl Pasteur No. 38, Bandung, Jawa Barat $4016 \mathrm{I}$, Indonesia

Tel +6222 2032530

Fax +6222 2039086

Email thusnitawati@gmail.com
Background and purpose: The prevalence of tuberculosis (TB) in Indonesia is still high, whereas the prevalence of extra pulmonary tuberculosis such as female genital tuberculosis (FGTB) affecting infertility is unknown. FGTB caused irreversible severe damaged of tubes and endometrium, resulting in tubal occlusion and partial or total obliteration of the uterine cavity. Diagnosis of FGTB is difficult. Therefore, a prompt diagnosis and treatment of pulmonary TB in women can prevent fertility complications. This study aims to analyze the correlation of clinical features taken from the history, physical examination, investigation of blood laboratory and gynecological ultrasound of pulmonary tuberculosis women with infertility.

Patients and methods: This was an observational analytic study with cross-sectional method. Subjects were women with pulmonary TB treated in TB-DOTS (tuberculosisdirectly observed treatment, short-course) services at Dr Hasan Sadikin Hospital Bandung during December 2016 until March 2017. Subjects were divided into two groups consist of 32 TB patients with infertility, and 35 TB patients without infertility.

Results: The results showed that clinical features such as intermenstrual bleeding, endometrial synechiae, hydrosalpinx and endometritis appearance were the difference between two groups ( $\mathrm{p}<0.001$ ), those clinical features had a moderate correlation with the incidence of pulmonary tuberculosis women.

Conclusion: Clinical features like endometrial synechia and ultrasound imaging such as hydrosalpinx and endometritis encountered in pulmonary and extra pulmonary tuberculosis patients with infertility can be used as a basis for the diagnosis of alleged genital TB.

Keywords: infertility, genital tuberculosis, ultrasonography

\section{Introduction}

In 1993 the World Health Organization (WHO) declared tuberculosis (TB) as a major health problem in the developing countries. ${ }^{1-4}$ According to a survey conducted by WHO in 2004, while TB patients visit to hospital in Indonesia reached $60 \%$, the treatment success is still below $50 \%$ due to high dropout rate (50-80\%). According to data obtained from the Indonesian Ministry of Health's Data and Information Center, the prevalence of pulmonary and extra pulmonary TB in Indonesia in 2014 was 224 cases per 100000 population. $^{4-6}$

Extrapulmonary TB, for example genital TB, has various prevalences worldwide. The lowest incidence was in Australia (0.69\%) while the highest is in India $(19 \%)$. No data from Indonesia was available. ${ }^{3-5}$ 
Female genital TB occurs primarily by hematogenous spread from focus in the lungs. ${ }^{6-8}$ Focal infection in the fallopian tube causes tubal obstruction, tubal dilatation and thickening of the fallopian tubes. Focal infection in the endometrium causes endometritis. Genital TB could result in infertility.

Infertility is defined as the failure to achieve a clinical pregnancy after 12 months or more of regular unprotected sexual intercourse. Infertility could be caused by female factors involving the uterine factor, fallopian tube factor, and ovarian reserve. ${ }^{9-12}$ Male factors are responsible in $20 \%$ cases while $10 \%$ is due to unexplained infertility. Direct infection is responsible in only $1 \%$ of genital TB through sexual contact with genital TB patients, and TB orchitis causes oligospermia to azoospermia.

The constitutional symptoms of genital tuberculosis are not different from the constitutional symptoms of pulmonary TB such as weakness, weight loss, and history of contact with TB patients. Infertility is the most common disorder in genital TB cases. Reported history of menstrual disorders such as intermenstrual bleeding and amenorrhea, along with clinical findings of endometrial synechiae accompanying infertility in patients with TB constitutional symptoms can be used in establishing the diagnosis of alleged genital TB. ${ }^{6,11,13}$

Ultrasound is used to confirm the diagnosis of genital tuberculosis. Focal infection of the fallopian tube causing obstruction at ultrasound examination is described as hydrosalpinx. Hydrosalpinx appears as tubal dilatation with septae due to tubal mucosa thickening (cogwheel appearance). The focus of infection on the endometrium is described as endometritis, i.e., thin, diffuse endometrial images, with irregular borders, and accompanied by fluid accumulation in the uterine cavity. Hysterosalpingography (HSG) can diagnose genital TB by finding a hydrosalpinx image resembling a tobacco leaf, and a uterus resembling a honeycomb image caused by multiple diverticuli.

Based on several existing literatures, the diagnosis of genital tuberculosis is generally established by surgery such as laparoscopy or laparoscopic biopsy and endometrial curettage to find Mycobacterium tuberculosis on microbiological, or histopathological features of granuloma and Langerhans cells. This method is difficult to perform due to its invasive nature and not being covered under the national health insurance. ${ }^{4,6,12,14,15}$ The high index of suspicion method by combining and analyzing the relationship between clinical findings on physical examination and simple daily additional examination with infertility incidence is expected to facilitate the diagnosis of alleged cases of genital TB. ${ }^{1-3}$

Thoroughly treating all pulmonary and extrapulmonary tuberculosis patients serves an important role. It can prevent hematogenous spread to the internal genitalia, thus avoiding irreversible damage brought by tubal obstruction and tuberculous endometritis. This may improve the likelihood of spontaneous pregnancy prior to resorting to assisted reproductive technologies. ${ }^{8,9}$

\section{Materials and Methods}

This research was an analytic observational research with cross-sectional research design. It was conducted at Dr. Hasan Sadikin Hospital between December 2016 and March 2017. Subjects were taken by consecutive sampling of reproductive age women presenting to DOTS outpatient clinic, having previously been diagnosed with pulmonary and/or extra-pulmonary TB.

The patients were given informed consent before the study. Patient history including parity, marital history, history of menstruation, and history of infertility was collected. Physical examination was performed with findings confirmed using gynaecological ultrasound. Patient's hematological lab results were also collected.

Analytical statistics to assess the differences between the patient groups and measure the correlation of clinical and ultrasound findings with infertility was performed using the software Statistical Package for Social Sciences (SPSS) version 21.0 for Windows. Database spreadsheets were generated using Microsoft Excel.

\section{Results}

There were 67 patients included and divided into two groups: 32 infertile tuberculosis patients and 35 patients with fertile tuberculosis (Table 1). The subjects were between 20 and 45 years old. Most infertile patients were between 20 and 29 years old while most fertile patients were between 30-39 years old. Pulmonary tuberculosis and tuberculous lymphadenitis were the most common types of tuberculosis among infertile and fertile TB patients, respectively.

Infertile TB patients had significantly more intermenstrual bleeding and endometrial synechiae than fertile TB patients ( $p<0.05$ and $p<0.001$, respectively) (Table 2 ). Infertile TB patients also had significantly more hydrosalpinx and endometritis $(\mathrm{p}<0.001)$ (Table 3 ).

There was a moderate correlation with infertility among patients with endometrial synechiae $(\mathrm{r}=0.562)$; 
Table I Characteristics of Research Subjects

\begin{tabular}{|c|c|c|}
\hline \multirow[t]{2}{*}{ Characteristics } & \multicolumn{2}{|l|}{ Group } \\
\hline & $\begin{array}{l}\text { Infertile } \\
(n=32) N(\%)\end{array}$ & $\begin{array}{l}\text { Fertile } \\
(n=35) \text { N (\%) }\end{array}$ \\
\hline \multicolumn{3}{|l|}{ Age } \\
\hline $20-29$ & $20(62.5)$ & $10(28.5)$ \\
\hline $30-39$ & $12(37.5)$ & $17(48.6)$ \\
\hline$\geq 40$ & $0(0)$ & $8(22.9)$ \\
\hline \multicolumn{3}{|l|}{ Contraceptive Use } \\
\hline No & $0(0)$ & $13(37.1)$ \\
\hline Yes & $32(100)$ & $22(62.9)$ \\
\hline \multicolumn{3}{|l|}{ Tuberculosis Type } \\
\hline Pulmonary tuberculosis & $14(43.8)$ & II (3I.4) \\
\hline Tuberculous lymphadenitis & $8(25)$ & $15(42.9)$ \\
\hline Abdominal tuberculosis & $7(21.8)$ & $4(11.4)$ \\
\hline Tuberculous spondylitis & $I(3.1)$ & $3(8.5)$ \\
\hline Tuberculous meningitis & I (3.I) & I (2.9) \\
\hline Other type of tuberculosis & I (3.I) & I (2.9) \\
\hline
\end{tabular}

ultrasonographic features of hydrosalpinx $(\mathrm{r}=0.604)$, and endometriosis $(\mathrm{r}=0.583)$ (Table 4).

\section{Discussion}

Most infertile TB patients (62.5\%) were between 20 and 29 years old (Table 1). Another study had the same demographics, with most subjects between the age of 20 and 40 years with $47.8 \%$ infertility rate.

The highest infertility incidence was found among pulmonary TB patients $(43.8 \%)$ followed by tuberculous lymphadenitis (25\%) and abdominal TB (21.8\%) (Table 1). This suggests that having been established in the lungs, tuberculosis spread hematogenously to the reproductive organs. ${ }^{10,11}$

Table 2 The Clinical Findings of Genital Leucorrhea, Intermenstrual Bleeding, Amenorrhea, and Endometrial Synechia in Infertile and Fertile TB Patients

\begin{tabular}{|l|l|l|l|}
\hline \multirow{2}{*}{$\begin{array}{l}\text { Clinical } \\
\text { Features }\end{array}$} & \multicolumn{2}{|l|}{ Group } & \multirow{2}{*}{ * Value } \\
\cline { 2 - 3 } & $\begin{array}{l}\text { Infertile (n=32) } \\
\text { N (\%) }\end{array}$ & $\begin{array}{l}\text { Fertile (n=35) } \\
\text { N (\%) }\end{array}$ & \\
\hline $\begin{array}{l}\text { Leucorrhea } \\
\text { Intermenstual } \\
\text { bleeding }\end{array}$ & $3(9.4)$ & $4(11.4)$ & 1.000 \\
Amenorrhea & I3 (40.6) & $5(14.3)$ & 0.015 \\
$\begin{array}{l}\text { Endometrial } \\
\text { synechia }\end{array}$ & II (34.4) & $\begin{array}{l}5(14.3) \\
0(0.0)\end{array}$ & $\begin{array}{l}0.054 \\
<0.001\end{array}$ \\
\hline
\end{tabular}

Note: *Based on Chi-Square test.
Table 3 The Difference Between Ultrasonographic Imaging in the Form of Hydrosalpinx and Endometritis Between Infertile and Fertile TB Patients

\begin{tabular}{|l|l|l|l|}
\hline \multirow{2}{*}{$\begin{array}{l}\text { Ultrasonography } \\
\text { Imaging }\end{array}$} & \multicolumn{2}{|l|}{ Group } & \multirow{2}{*}{ * Value } \\
\cline { 2 - 3 } & $\begin{array}{l}\text { Infertile } \\
(\mathbf{n}=\mathbf{3 2}) \\
\mathbf{N}(\%)\end{array}$ & $\begin{array}{l}\text { Fertile } \\
(\mathbf{n}=\mathbf{3 5}) \\
\mathbf{N}(\%)\end{array}$ & \\
\hline $\begin{array}{l}\text { Hydrosalpinx } \\
\text { Endometritis }\end{array}$ & $20(62.5)$ & $\begin{array}{l}2(5.7) \\
\mathrm{I}(2.9)\end{array}$ & $<<0.00 \mathrm{I}$ \\
\hline
\end{tabular}

Note: *Based on Chi-Square test.

Table 4 The Relationship Between Clinical Features, Laboratory, and Ultrasound in Tuberculosis Patients with Infertility

\begin{tabular}{|l|l|l|}
\hline $\begin{array}{l}\text { Correlation of Risk Factors } \\
\text { with Infertility Incidence }\end{array}$ & $\begin{array}{l}\text { Correlation } \\
\text { Coefficient Phi }\end{array}$ & P value \\
\hline $\begin{array}{l}\text { Clinical Features } \\
\text { Intermenstrual bleeding }\end{array}$ & 0.297 & \\
Amenorrhea & 0.235 & 0.015 \\
Leucorrhea & -0.034 & 0.054 \\
Endometrial synechia & 0.562 & 1.0 \\
\hline Laboratory Finding & & $<0.001$ \\
Anemia & 0.112 & \\
Elevated ESR & 0.182 & 0.361 \\
\hline Ultrasonography Imaging & & 0.137 \\
Hydrosalpinx & 0.604 & \\
Endometritis & 0.583 & $<0.001$ \\
\hline
\end{tabular}

Abbreviation: ESR, erythrocyte sedimentation rate.

Then, tuberculous foci in the ovaries, tubes and endometrium disrupts sperm passage and destroys ovarian reserve, hampering fertilization. ${ }^{8}$ Such foci also led to menstrual abnormalities, affecting $20-50 \%$ infertile TB patients. ${ }^{9}$

Menstrual disorders are associated with weight loss, possible anti-gonadotropic effects and increased enzymatic catabolism of estrogen as a result of the focal infection in the ovaries and endometrium. The edematous endometrial layer is very susceptible to bleeding and present clinically as intermenstrual bleedings. ${ }^{11}$ If this condition persists, it can lead to endometrial adhesion and obliteration. This is reflected by the higher rates of both intermenstrual bleeding and endometrial synechiae among infertile TB patients.

By ultrasonography, $90.9 \%$ of infertile subjects had hydrosalpinx and $94.4 \%$ had endometritis. Tuberculous hydrosalpinx is described as dilatation of the tube with septa caused by the thickening of the tubal mucosa, known as cogwheel appearance, whereas endometritis is described when there is a presence of a thin layer of endometrium, with irregular 
edges, with discontinuity or even absence of endometrial line, and occasional fluid collection in the uterine cavity. ${ }^{10-12}$ Hydrosalpinx and endometritis confirms tuberculosis infection in the reproductive organs. This study found that genital TB could be suggested on the basis of finding ultrasound features of hydrosalpinx and endometritis in TB patients presenting with infertility.

This study showed the positive correlation between infertility among tuberculosis patients and the presence of endometrial synechiae, hydrosalpinx and endometritis on ultrasound. Previous research also reported a number of clinical and ultrasonographic features of the genitalia that may indicate TB influence on a patient's fertility. ${ }^{12}$ The presence of such clinical findings may aid in the diagnosis of genital TB.

\section{Conclusion}

Clinical features like endometrial synechia and ultrasound imaging such as hydrosalpinx and endometritis encountered in pulmonary and extrapulmonary tuberculosis patients with infertility can be used as a basis for the diagnosis of alleged genital TB.

\section{Ethics Statement}

This study protocol was approved by the Ethics Committee Review Board of Dr. Hasan Sadikin General Hospital - Faculty of Medicine, Universitas Padjadjaran. All study participants gave written consents to participate. All authors declare that all patients were examined in accordance to the ethical standards laid down in the 1964 Declaration of Helsinki.

\section{Consent for Publication}

All authors declare that written informed consent was obtained from every patient, regarding detail information and images to be described in this publication.

\section{Data Sharing Statement}

The authors declare that the personal data from any patients involved in this study will not be shared as they are patients' confidentialities.

\section{Author Contributions}

All authors contributed to data analysis, drafting and revising the article, gave final approval of version to be pub- lished, and agree to be accountable for all aspects of the work.

\section{Funding}

TH was supported by the Grants-in-Aid from the Ministry of Research, Technology and Higher Education of the Republic of Indonesia No. 01/E/KPT/2018 (PUPT).

\section{Disclosure}

The authors report no conflicts of interest in this work.

\section{References}

1. Sanches I, Carvalho A, Duarte R. Who are the patients with extrapulmonary tuberculosis? Rev Portuguesa de Pneumologia (Engl Ed). 2015;21(2):90-93. doi:10.1016/j.rppnen.2014.06.010

2. Lee JY. Diagnosis and treatment of extrapulmonary tuberculosis. Tuberc Respir Dis (Seoul). 2015;78(2):47-55. doi:10.4046/ $\operatorname{trd}$.2015.78.2.47

3. WHO. Global Tuberculosis Report 2015. World Health Organization;2015.

4. Medical Record of Dr. Hasan Sadikin Hospital. Medical record data of tuberculosis patients in Dr. Hasan Sadikin Hospital year 2015; 2015.

5. WHO. Systematic Screening for Active Tuberculosis: Principles and Recommendations. World Health Organization; 2013.

6. Sharma JB. Current diagnosis and management of female genital tuberculosis. J Obstet Gynecol India . 2015;65(6):362-371.

7. Patel S, Dhand P. A hospital based study on female genital tuberculosis in central India. Int J Med Res Rev. 2016;4(02):227-232.

8. Kulshrestha V, Kriplani A, Agarwal N, Singh UB, Rana T. Genital tuberculosis among infertile women and fertility outcome after antitubercular therapy. Int J Gynaecol Obstet . 2011;113(3):229-234. doi:10.1016/j.ijgo.2010.12.014

9. Shahzad S. Investigation of prevalence of female genital tract tuberculosis and its relation to female infertility: an observational analytical study. Iran J Reprod Med. 2012;10(6):581-588.

10. Eftekhar M, Pourmasumi S, Sabeti P, Aflatoonian A, Sheikhha MH. Mycobacterium tuberculosis infection in women with unexplain infertility. Int J Reprod Biomed (Yazd). 2015;13(12):749-754.

11. Shafee M, Abbas F, Ashraf M, et al. Hematological profile and risk factors associated with pulmonary tuberculosis patients in Quetta, Pakistan. Pak J Med Sci. 2014;30(1):36. doi:10.12669/pjms.306.5684

12. Usharani B, Muthuraj M, Radhakrishnan B, James JB, Govindarajan S, Raman KV. Molecular epidemiology of female genital tuberculosis leading to infertility. Int J Curr Microbiol App Sci. 2016;5(8):731-740. doi:10.20546/ijcmas

13. Grace GA, Devaleenal DB, Natrajan M. Genital tuberculosis in females. Indian J Med Res. 2017;145(4):425-436. doi:10.4103/ijmr. IJMR_1550_15

14. Malhotra B, Sinha P, Hooja S, Vyas L. Rapid diagnosis of genital tuberculosis by real time polymerase chain reaction. $J$ South Asian Feder Obst and Gynae. 2012;4:39-42.

15. Shah HU, Sannananja B, Baheti AD, Udare AS, Badhe PV. Hysterosalpingography and ultrasonography findings of female genital tuberculosis. Diagn Interv Radiol. 2015;21:10-15. doi:10.5152/dir 


\section{Publish your work in this journal}

The International Journal of General Medicine is an international, peer-reviewed open-access journal that focuses on general and internal medicine, pathogenesis, epidemiology, diagnosis, monitoring and treatment protocols. The journal is characterized by the rapid reporting of reviews, original research and clinical studies

across all disease areas. The manuscript management system is completely online and includes a very quick and fair peer-review system, which is all easy to use. Visit http://www.dovepress.com/ testimonials.php to read real quotes from published authors. 